\title{
Ausländische Staaten vor deutschen Zivilgerichten
}

Zum Spannungsverhältnis von Staatenimmunität und Recht auf Zugang zu Gericht

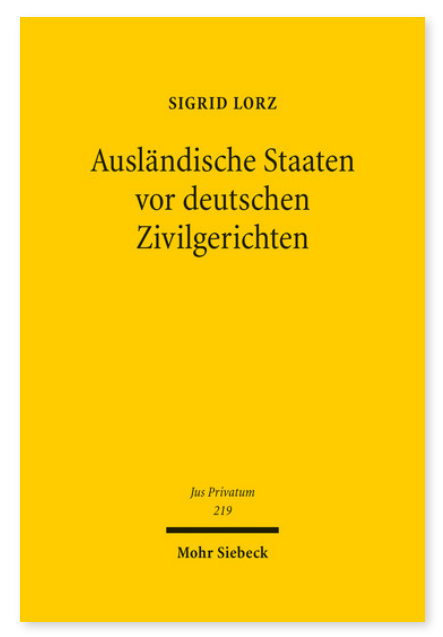

2017. XXIV, 499 Seiten. JusPriv 219

ISBN 978-3-16-155549-7

DOI 10.1628/978-3-16-155549-7

eBook PDF 129,00€

ISBN 978-3-16-155548-0

Leinen $129,00 €$
Private Gläubiger ersuchen zunehmend die deutschen Zivilgerichte um Rechtsschutz gegenüber ausländischen Staaten, um ihre Ansprüche aus Staatsanleihen oder Investitionsschutzabkommen durchzusetzen. Hierbei stehen die Gerichte vor der Herausforderung, sowohl der Stellung eines ausländischen Staates als souveränes und gleichwertiges Völkerrechtssubjekt angemessen Rechnung zu tragen als auch dem privaten Gläubiger effektiven Rechtsschutz zu gewähren. Sigrid Lorz zeigt die Besonderheiten auf, die es bei der Beteiligung eines ausländischen Staates an einem Zivilprozess zu beachten gilt, und erörtert Lösungsmöglichkeiten für daraus resultierende Problemkonstellationen. Die Auswirkungen des Völkerrechts auf das Zivilprozessrecht betreffen dabei das gesamte zivilprozessuale Verfahren: angefangen von der Klagezustellung über die Frage nach vollstreckungstauglichen Gegenständen bis hin zu den Rechtsschutzmöglichkeiten.

Sigrid Lorz Geboren 1978; Studium der Rechtswissenschaft in Erlangen und Dublin; 2006 Promotion; Referendariat in Nürnberg und Berlin; 2008-11 Richterin und Staatsanwältin; 2016 Habilitation; derzeit Akademische Oberrätin a.Z. an der Universität Erlangen-Nürnberg.

Jetzt bestellen:

https://mohrsiebeck.com/buch/auslaendische-staaten-vor-deutschen-zivilgerichten-9783161555497?no_cache=1 order@mohrsiebeck.com

Telefon: +49 (0)7071-923-17

Telefax: $+49(0) 7071-51104$ 